\title{
KCNQ Channels Determine Serotonergic Modulation of Ventral Surface Chemoreceptors and Respiratory Drive
}

\author{
Joanna M. Hawryluk, ${ }^{1}$ Thiago S. Moreira, ${ }^{2}$ Ana C. Takakura, ${ }^{3}$ Ian C. Wenker, ${ }^{1}$ Anastasios V. Tzingounis, ${ }^{1 *}$ \\ and Daniel K. Mulkey ${ }^{1 \star}$ \\ ${ }^{1}$ Department of Physiology and Neurobiology, University of Connecticut, Storrs, Connecticut 06269, and Departments of 2Physiology and Biophysics and \\ ${ }^{3}$ Pharmacology, University of São Paulo, São Paulo, São Paulo, 05508, Brazil
}

\begin{abstract}
Chemosensitive neurons in the retrotrapezoid nucleus (RTN) regulate breathing in response to $\mathrm{CO}_{2} / \mathrm{H}^{+}$changes. Their activity is also sensitive to neuromodulatory inputs from multiple respiratory centers, and thus they serve as a key nexus of respiratory control. However, molecular mechanisms that control their activity and susceptibility to neuromodulation are unknown. Here, we show in vitro and in vivo that KCNQ channels are critical determinants of RTN neural activity. In particular, we find that pharmacological block of KCNQ channels (XE991, $10 \mu \mathrm{M}$ ) increased basal activity and $\mathrm{CO}_{2}$ responsiveness of RTN neurons in rat brain slices, whereas KCNQ channel activation (retigabine, 2- $40 \mu \mathrm{M}$ ) silenced these neurons. Interestingly, we also find that KCNQ and apamin-sensitive SK channels act synergistically to regulate firing rate of RTN chemoreceptors; simultaneous blockade of both channels led to a increase in $\mathrm{CO}_{2}$ responsiveness. Furthermore, we also show that KCNQ channels but not SK channels are downstream effectors of serotonin modulation of RTN activity in vitro. In contrast, inhibition of KCNQ channel did not prevent modulation of RTN activity by Substance P or thyrotropin-releasing hormone, previously identified neuromodulators of RTN chemoreception. Importantly, we also show that KCNQ channels are critical for RTN activity in vivo. Inhibition of KCNQ channels lowered the $\mathrm{CO}_{2}$ threshold for phrenic nerve discharge in anesthetized rats and decreased the ventilatory response to serotonin in awake and anesthetized animals. Given that serotonergic dysfunction may contribute to respiratory failure, our findings suggest KCNQ channels as a new therapeutic avenue for respiratory complications associated with multiple neurological disorders.
\end{abstract}

\section{Introduction}

The retrotrapezoid nucleus (RTN) functions as a key locus for respiratory control. Neurons in this nucleus regulate respiratory drive in response to changes in tissue $\mathrm{CO}_{2} / \mathrm{H}^{+}$(i.e., they function as respiratory chemoreceptors; (Feldman et al., 2003; Mulkey et al., 2004), and serve as a point of convergence for respiratory drive from peripheral chemoreceptors (Takakura et al., 2006) and multiple other brain regions involved in respiration (Mulkey et al., 2007a; Dias et al., 2009). Activity of RTN chemoreceptors, and consequently respiratory drive, is particularly sensitive to input from serotonergic neurons. The RTN receives dense innervation from raphe nuclei and raphe transmitters including serotonin which have been shown to activate RTN neurons and increase respiratory output (Mulkey et al., 2007b). Disruption of serotonergic drive to respiratory centers such as the RTN is

\footnotetext{
Received June 27, 2012; revised Sept. 26, 2012; accepted Sept. 27, 2012.

Author contributions: A.V.T. and D.K.M. designed research; J.M.H., T.S.M., A.C.T., and I.C.W. performed research; J.M.H., T.S.M., A.C.T., A.V.T., and D.K.M. analyzed data; T.S.M., A.V.T., and D.K.M. wrote the paper.

This work was supported by CURE Epilepsy Foundation (A.V.T., D.K.M.), National Institutes of Health Grants HL104101 (D.K.M.) and NS073981 (A.V.T.), American Heart Association Grant 11PRE7580037 (I.C.W.), and the Sa0 Paulo Research Foundation (FAPESP) (A.C.T., T.S.M.). We thank Drs. Karen Menuz, Douglas Bayliss, and Patrice Guyenet for their comments on the manuscript.

*A.V.T. and D.K.M. are co-senior authors.

Correspondence should be addressed to Anastasios V. Tzingounis or Daniel K. Mulkey at the above address. E-mail: daniel.mulkey@uconn.edu or anastasios.tzingounis@uconn.edu.

DOI:10.1523/JNEUROSCI.3043-12.2012

Copyright $\odot 2012$ the authors $\quad 0270-6474 / 12 / 3216943-10 \$ 15.00 / 0$
}

thought to contribute to respiratory deficits associated with multiple neurological disorders, including attenuated respiratory chemoreflex (Ray et al., 2011), sudden unexpected death in epilepsy, and sudden infant death syndrome (Buchanan and Richerson, 2010). Despite this critical physiological role, little is known about the downstream effectors responsible for the serotonin-induced increase in RTN chemoreceptor activity. Serotonergic modulation has been suggested to act through the 5- $\mathrm{HT}_{2}$ family of Gq-coupled receptors (Mulkey et al., 2007b), but the ion channel targets of $\mathrm{Gq}$ signaling are completely unknown.

Voltage-gated KCNQ and $\mathrm{Ca}^{2+}$-activated small conductance $\mathrm{K}^{+}(\mathrm{SK})$ channels have a high propensity for neuromodulation. For example, KCNQ and SK channels are downstream targets of multiple G-protein-coupled receptors (Delmas and Brown, 2005; Adelman et al., 2011). In particular, Gq signaling in multiple cell types is known to inhibit the M-current that is mediated by KCNQ2/KCNQ3 channels (Wang et al., 1998; Shapiro et al., 2000). Considering that the M-current is active at subthreshold membrane potentials, inhibition of KCNQ channels can increase neuronal excitability (Brown and Adams, 1980; Delmas and Brown, 2005). In addition, KCNQ and SK channels can influence excitability by regulating amplitude of the medium afterhyperpolarization (mAHP) (Bond et al., 2004; Peters et al., 2005). Given immunohistochemical evidence indicating KCNQ and SK expression in the brainstem (Cooper et al., 2001; Sailer et al., 2004), we wondered whether KCNQ or SK channels are responsible for the precise control of RTN chemoreceptor activity in 
response to neuromodulation. We therefore investigated the functional roles of KCNQ and SK channels at the cellular and systems level in the RTN as well as tested their involvement in serotonergic neuromodulation.

Here, we demonstrate that KCNQ channels, but not SK channels, contribute to RTN chemoreceptor spontaneous activity and serve as downstream effectors of serotonergic modulation in vitro. Likewise, we find that inhibition of KCNQ channels in the RTN decrease the ventilatory response to serotonin in both anesthetized and conscious animals. To our knowledge, these data represent the first evidence for transmitter modulation of KCNQ channels in vivo. Further, we show that although KCNQ and SK channels are not molecular correlates of the $\mathrm{CO}_{2} / \mathrm{H}^{+}$-sensitive potassium conductance in RTN neurons, together these channels can indirectly influence $\mathrm{CO}_{2}$ responsiveness by regulating RTN neuron excitability. Given the profound influence that KCNQ channels have on RTN chemoreceptors and the role that serotonergic dysfunction has in respiratory failure, KCNQ channels may represent useful therapeutic targets for the treatment of respiratory control disorders.

\section{Materials and Methods}

Animals

Animal use was in accordance with guidelines approved by the University of Connecticut and University of São Paulo Institutional Animal Care and Use Committee. The majority of in vivo experiments were done on male Wistar rats weighing 250-300 g (8-10 months old). A limited number of in vivo experiments were performed in juvenile Wistar rats weighing 75-90 g. In vitro experiments were done on neonatal rat brain slices ( $7-12 \mathrm{~d}$ postnatal).

\section{Brain slice preparation and slice-patch electrophysiology}

Slices containing the RTN were prepared as previously described (Mulkey et al., 2004). Briefly, neonatal rats were decapitated under ketamine/xylazine anesthesia, and transverse brainstem slices $(300 \mu \mathrm{m})$ were cut using a microslicer (DSK 1500E; Dosaka) in ice-cold substituted Ringer solution containing (in $\mathrm{mm}$ ): 260 sucrose, $3 \mathrm{KCl}, 5 \mathrm{MgCl}_{2}, 1$ $\mathrm{CaCl}_{2}, 1.25 \mathrm{NaH}_{2} \mathrm{PO}_{4}, 26 \mathrm{NaHCO}_{3}, 10$ glucose, and 1 kynurenic acid. Slices were incubated for $\sim 30 \mathrm{~min}$ at $37^{\circ} \mathrm{C}$ and subsequently at room temperature in normal Ringer solution (in $\mathrm{mm}$ ): $130 \mathrm{NaCl}, 3 \mathrm{KCl}, 2$ $\mathrm{MgCl}_{2}, 2 \mathrm{CaCl}_{2}, 1.25 \mathrm{NaH}_{2} \mathrm{PO}_{4}, 26 \mathrm{NaHCO}_{3}$, and 10 glucose. Both substituted and normal Ringer solutions were bubbled with 95\% $\mathrm{O}_{2}-5 \%$ $\mathrm{CO}_{2}$, extracellular $\mathrm{pH} 7.35$.

Individual slices were transferred to a recording chamber mounted on a fixed-stage microscope (Zeiss Axioskop FS) and perfused continuously $\left(\sim 2 \mathrm{ml} \mathrm{min}^{-1}\right)$ with normal Ringer solution bubbled with $95 \% \mathrm{O}_{2}-5 \%$ $\mathrm{CO}_{2}$. The $\mathrm{pH}$ of the bath solution was decreased to 6.90 by bubbling with $15 \% \mathrm{CO}_{2}$. All recordings were made with an Axopatch 200B patch-clamp amplifier, digitized with a Digidata $1322 \mathrm{~A}$ A/D converter, and recorded using pCLAMP 10.0 software (Molecular Devices). Recordings were obtained at room temperature $\left(\sim 22^{\circ} \mathrm{C}\right)$ with patch electrodes pulled from borosilicate glass capillaries (Warner Instruments) on a two-stage puller (P89; Sutter Instrument) to a DC resistance of 4-6 M $\Omega$ when filled with an internal solution containing the following (in $\mathrm{mm}$ ): $120 \mathrm{KCH}_{3} \mathrm{SO}_{3}, 4$ $\mathrm{NaCl}, 1 \mathrm{MgCl}_{2}, 0.5 \mathrm{CaCl}_{2}, 10$ HEPES, 10 EGTA, $3 \mathrm{Mg}$-ATP, and 0.3 GTP-Tris ( $\mathrm{pH}$ 7.2); electrode tips were coated with Sylgard 184 (Dow Corning). All recordings of neuronal firing rate were performed using the cell-attached configuration in which a tight seal is formed but not ruptured, thus minimizing alteration of the intracellular milieu. Note that this configuration is conducive to cell excitability; however, action potentials will appear truncated because the membrane patch acts as a low-pass filter (Perkins KL, 2006). Firing rate histograms were generated by integrating action potential discharge in $10 \mathrm{~s}$ bins and plotted using Spike 5.0 software. Amplitude of the mAHP was measured in the wholecell configuration using an internal solution containing the following (in $\mathrm{mm}$ ): 120 potassium methylsulfate, $20 \mathrm{KCl}, 10 \mathrm{HEPES}, 4 \mathrm{NaCl}, 0.5 \mathrm{EGTA}$, $0.3 \mathrm{CaCl}_{2}, 4 \mathrm{Mg}$-ATP, and 0.3 Na-GTP, pH 7.2).

\section{In vivo preparation}

Anesthetized rats. The surgical procedures and experimental protocols were done in bilaterally vagotomized, artificially ventilated rats anesthetized with urethane and prepared as described previously (Mulkey et al., 2004). Briefly, general anesthesia was induced with $5 \%$ halothane in $100 \% \mathrm{O}_{2}$. Artificial ventilation with $1.4-1.5 \%$ halothane in $100 \% \mathrm{O}_{2}$ was maintained throughout surgery. The surgical procedures (bilateral vagotomy, arterial cannulation, phrenic nerve dissection, and dorsal transcerebellar access to the ventrolateral medulla oblongata) were standard. After surgery, halothane was gradually replaced by urethane $(1.2 \mathrm{~g} / \mathrm{kg}$, administered i.v. over $20 \mathrm{~min}$ ). This initial dose was supplemented hourly and at least twice with an injection of $0.1 \mathrm{~g} / \mathrm{kg}$. After a total of $1.4-1.5 \mathrm{~g} / \mathrm{kg}$, the level of anesthesia was stable for the rest of the experiment (up to $5 \mathrm{~h}$ after the initial anesthetic crossover). The rats were ventilated with $100 \% \mathrm{O}_{2}$ throughout the experiment and muscle relaxation was performed with pancuronium ( $1 \mathrm{mg} / \mathrm{kg}$ i.v.). Rectal temperature was maintained at $37^{\circ} \mathrm{C}$, and end-tidal $\mathrm{CO}_{2}\left(\mathrm{etCO}_{2}\right)$ was monitored throughout the experiment with a microcapnometer. The adequacy of anesthesia was continually monitored by testing for the absence of arterial pressure (AP) or phrenic nerve discharge (PND) responses to firm toe or tail pinch. After these criteria were satisfied, the muscle relaxant pancuronium was administered at an initial dose of $1 \mathrm{mg} / \mathrm{kg}$ i.v., and the adequacy of the anesthesia was thereafter gauged solely by the lack of increase in AP and PND rate or amplitude to a firm toe pinch.

Conscious rats. Rats were anesthetized with intraperitoneal injection of ketamine $(80 \mathrm{mg} / \mathrm{kg})$ combined with xylazine $(7 \mathrm{mg} / \mathrm{kg})$ and placed in a stereotaxic frame (model 900; David Kopf Instruments). Bilateral stainless steel cannulas were implanted into the RTN using the coordinates 2.5 $\mathrm{mm}$ caudal to lambda, $1.8 \mathrm{~mm}$ lateral to the midline, and $7.5 \mathrm{~mm}$ below dura mater. The cannulas were fixed to the cranium using dental acrylic resin and jeweler screws. Rats received a prophylactic dose of penicillin (30,000 IU) given intramuscularly and a subcutaneous injection of the analgesic Ketoflex $(1 \%, 0.03 \mathrm{ml} / \mathrm{rat})$ postsurgically. After the surgery, the rats were maintained in individual boxes with free access of tap water and food pellets.

Pulsatile arterial pressure, mean arterial pressure (MAP), and heart rate were recorded in unanesthetized, freely moving rats as described previously (Favero et al., 2011). Briefly, one day before the experiments, under intraperitoneal injection of ketamine $(80 \mathrm{mg} / \mathrm{kg})$ combined with xylazine $(7 \mathrm{mg} / \mathrm{kg})$ anesthesia, a polyethylene tubing (PE-10 connected to PE-50) was inserted into the abdominal aorta through the femoral artery. The cannula was tunneled subcutaneously to the back of the rats to allow access in unrestrained, freely moving rats.

\section{In vivo recordings of physiological variables}

Anesthetized rats. As described previously (Mulkey et al., 2004), MAP, $\mathrm{PND}$, and etCO $\mathrm{C}_{2}$ were digitized with a Micro 1401 (Cambridge Electronic Design), stored on a computer, and processed off-line with Spike 2 software. Integrated phrenic nerve discharge ( $\left.\int \mathrm{PND}\right)$ was obtained after rectification and smoothing $(\tau=0.015 \mathrm{~s})$ of the original signal, which was acquired with a $30-300 \mathrm{~Hz}$ bandpass filter. PND amplitude and frequency were expressed for each animal on a scale from 0 (value during apnea) to 100 (value while breathing $10 \% \mathrm{CO}_{2}$ ). As a reflection of total respiratory output, we calculated minute ventilation PND (mvPND) as the product of $\int$ PND frequency and amplitude. Diaphragmatic electromyography was used to measure respiratory activity in anesthetized juvenile rats (75-90 g). Two thin Teflon-coated silver wires with bared tips forming a $2 \mathrm{~mm}$ hook were inserted through the lateral edge of the diaphragm on the right side of the animals using $25 \mathrm{G} \times 5 / 8$ inch hypodermic needles. The electrode tips were inserted no more than $2-4$ $\mathrm{mm}$ apart to minimize the EKG artifact.

Serotonin was injected by pressure ( $40-60 \mathrm{psi}, 4 \mathrm{~ms}$ pulses, $50 \mathrm{nl}$ in $3-5 \mathrm{~s})$ through glass pipettes ( $20 \mu \mathrm{m}$ outside diameter) filled with serotonin creatinine sulfate ( $1 \mathrm{~mm}$ in $\mathrm{pH} 7.3$ normal saline with addition of a $1 \%$ dilution of fluorescent microbeads for histological verification of injection sites). The concentration of serotonin used in these experiments was based on the $\mathrm{EC}_{50}$ response elicited by 5 -HT injections into the hypoglossal nucleus of anesthetized rats (Fenik and Veasey, 2003). The pipette tip was placed $200 \mu \mathrm{m}$ below the caudal edge of the facial 
motor nucleus under electrophysiological guidance. Postmortem histological inspection of the location of fluorescent microbeads verified the correct placement of the injections in all cases.

Conscious rats. Twenty-four hours after cannulation, when the rats were completely recovered from the surgery and adapted to the environment of the recording room, the arterial catheter was connected to a pressure transducer coupled to a preamplifier that was connected to a PowerLab computer data acquisition system (ADInstruments).

Respiratory rate (fR, breaths $/ \mathrm{min}$ ) and tidal volume $(\mathrm{VT}, \mathrm{ml} / \mathrm{kg}$ ) in conscious, freely moving rats were measured by whole-body plethysmography as described previously (Malan, 1973). All experiments were performed at room temperature $\left(24-26^{\circ} \mathrm{C}\right)$. In brief, freely moving rats were kept in a Plexiglas recording chamber $(5 \mathrm{~L})$ that was flushed continuously with a mixture of $79 \%$ nitrogen and $21 \%$ oxygen (unless otherwise required by the protocol) at a rate of $1 \mathrm{~L} / \mathrm{min}$. Concentrations of $\mathrm{O}_{2}$ and $\mathrm{CO}_{2}$ in the chamber were monitored on-line using a fastresponse $\mathrm{O}_{2} / \mathrm{CO}_{2}$ monitor (ADInstruments). The pressure signal was amplified, filtered, recorded, and analyzed off-line using PowerLab software (ADInstruments). Animals were allowed $\sim 30 \mathrm{~min}$ to acclimatize to the chamber environment at normoxia/normocapnia $\left(21 \% \mathrm{O}_{2}, 79 \% \mathrm{~N}_{2}\right.$, and $<0.5 \% \mathrm{CO}_{2}$ ) before measurements of baseline arterial pressure and ventilation were taken. Hypercapnia was induced by titrating $\mathrm{CO}_{2}$ into the respiratory mixture up to a level of $8-10 \%$ for $10 \mathrm{~min}$. Measurements of respiratory frequency, $\mathrm{fR}$, and tidal volume, VT, were taken during the last $2 \mathrm{~min}$ before exposure to the stimulus and during the $2 \mathrm{~min}$ period at the end of each stimulus, when breathing stabilized. Changes in the $\mathrm{fR}$, $\mathrm{VT}$, and minute ventilation $(\mathrm{VE})(\mathrm{fR} \times \mathrm{VT} ; \mathrm{ml} / \mathrm{min} / \mathrm{kg})$ were averaged and expressed as means \pm SE.

\section{Histology}

At the end of each in vivo experiment, rats were deeply anesthetized with halothane and perfused through the heart with PBS, pH 7.4, followed by paraformaldehyde ( $4 \%$ in $0.1 \mathrm{~m}$ phosphate buffer, $\mathrm{pH} 7.4$ ). The brains were removed and stored in fixative for $24 \mathrm{~h}$ at $4^{\circ} \mathrm{C}$. The medulla was cut in $40-\mu \mathrm{m}$-thick coronal sections with a vibrating microtome (Vibratome $1000 \mathrm{~S}$ Plus). Sections were stored at $-20^{\circ} \mathrm{C}$ in a cryoprotectant solution. The injections sites were confirmed with an Axioskop 2 microscope (Zeiss). Sections from different brains were aligned with respect to a reference section, which was the most caudal section containing an identifiable cluster of facial motor neurons. To this reference section was assigned a value of $11.6 \mathrm{~mm}$ caudal to bregma (bregma $-11.6 \mathrm{~mm}$; Paxinos and Watson, 1989). Levels rostral or caudal to this reference section were determined by adding or subtracting the number of intervening sections $\times 40 \mu \mathrm{m}$.

\section{Statistical analysis}

Data are reported as mean \pm standard error of the mean. Statistical analysis was performed using Sigma Stat version 3.0 software. A $t$ test, unpaired $t$ test, or repeated measures one-way ANOVA followed by the Newman-Keuls multiple-comparisons test were used as appropriate $(p<0.05)$. The relevant values used for statistical analysis are provided in the results section.

\section{Results \\ KCNQ and SK channels are expressed by RTN chemoreceptors}

To determine whether KCNQ and SK channels are expressed by RTN chemoreceptors, we used the selective blockers XE991 and apamin, respectively (Bond et al., 2004; Peters et al., 2005). Cellattached patch recordings were used to identify RTN chemoreceptors in acute brainstem slices by their characteristic response to $\mathrm{CO}_{2}$; they are spontaneously active under control conditions $\left(0.3 \pm 0.1 \mathrm{~Hz}, 5 \% \mathrm{CO}_{2}\right)$ and show robust firing in responses to $15 \% \mathrm{CO}_{2}(1.9 \pm 0.2 \mathrm{~Hz})$. Depolarizing pulses were then delivered in whole-cell mode to evoke a mAHP in the presence of $5 \mu \mathrm{M}$ tetrodotoxin to silence network activity (Fig. 1A). Application of apamin $(100 \mathrm{nM})$ reduced the $\mathrm{mAHP}$ amplitude by $\sim 50 \%$, and additional application of XE991 $(10 \mu \mathrm{M})$ substantially reduced the remaining $\mathrm{mAHP}\left(F_{(2,22)}=21.1, p<0.01\right)$. In separate experiments, we found that bath application of the KCNQ channel agonist retigabine inhibited chemoreceptor activity with high affinity $\left(\mathrm{IC}_{50}=0.6 \mu \mathrm{M}\right)$ (Fig. $1 \mathrm{~B} 1$ ), as expected for activation of KCNQ2-5 channels (Wickenden et al., 2000). Together, these results indicate that both KCNQ and SK channels are expressed by RTN chemoreceptors.

\section{KCNQ channels regulate tonic activity and serotonin-modulation of RTN neurons in vitro}

To gain insight into the contributions of KCNQ and SK channels to resting excitability of RTN chemoreceptors, we first investigated effects of XE991 and apamin on baseline firing behavior and $\mathrm{CO}_{2} / \mathrm{H}^{+}$sensitivity using the cell-attached configuration. Bath application of XE991 $(10 \mu \mathrm{M})$ increased neuronal firing rate by $1.6 \pm 0.2 \mathrm{~Hz}\left(T_{20}=-7.2, p<0.01\right)$ (Fig. 1B2,C2). Similarly, exposure to $2 \mu \mathrm{M}$ XE991 increased firing rate from $0.2 \pm 0.1$ to $1.1 \pm 0.03 \mathrm{~Hz}\left(T_{2}=-7.6, p<0.05\right)$, further suggesting that KCNQ channels specifically tune the RTN basal firing rate. In addition, XE991-stimulated activity could be eliminated by coapplication of retigabine $(40 \mu \mathrm{M})$ (Fig. $1 \mathrm{~B} 2)$, thus adding to the possibility that activity of RTN chemoreceptors is regulated by retigabine-sensitive KCNQ channels (e.g., KCNQ2-5). Furthermore, XE991-mediated activation of RTN chemoreceptors resulted in a parallel leftward shift in $\mathrm{CO}_{2}$ responsiveness and increased activity at 5 and $10 \% \mathrm{CO}_{2}\left(F_{(5,29)}=16.9, p<0.01\right)$, but without altering the maximum $\mathrm{CO}_{2}$-induced change in RTN firing rate (Fig. 1C2). This suggests that KCNQ channels may not contribute to the mechanism by which RTN neurons sense $\mathrm{CO}_{2}$ changes. To directly test this assertion, we measured responsiveness to a maximal level of $\mathrm{CO}_{2}(15 \%)$ when KCNQ channels are blocked with XE991 $(10 \mu \mathrm{M})$ and the baseline firing rate is adjusted to near control levels by DC current injection as described previously (Wenker et al., 2012). In the continued presence of XE991, $\mathrm{CO}_{2}$ exposure increased activity by $1.9 \pm 0.2 \mathrm{~Hz}\left(T_{16}=\right.$ $-7.3, p<0.01)$, an amount similar to that of $\mathrm{CO}_{2}$ responsiveness in the absence of XE991 (Fig. 1C1). These results indicate that KCNQ channels are not essential to the $\mathrm{CO}_{2}$-sensing mechanism per se but do regulate excitability of RTN neurons and consequently influence their response to changes in $\mathrm{CO}_{2}$. In contrast, application of apamin $(100 \mathrm{nM})$ alone had no effect on either baseline firing activity $\left(T_{18}=1.6, p=0.14\right)$ or $\mathrm{CO}_{2}$ sensitivity $\left(T_{18}=-0.36, p=0.72\right)$ (Fig. $\left.1 D\right)$. Considering that KCNQ channels exhibit strong voltage-dependent activation and are known to temper stimulated neural activity, our evidence that XE991 did not affect 15\% $\mathrm{CO}_{2}$ responsiveness in RTN neurons further suggests that other channels limit stimulated activity of RTN neurons. It is well established that SK channels activate in response to increases in the neuronal firing rate. Therefore, we also considered the possibility that KCNQ and SK channels function in concert to limit elevated chemoreceptor activity. To test this hypothesis, we examined $\mathrm{CO}_{2}$-evoked activity under conditions when both SK and KCNQ channels were blocked. We found that application of apamin in the presence of XE991 increased neuronal responsiveness to $\mathrm{CO}_{2}$; in XE991, exposure to $15 \% \mathrm{CO}_{2}$ increased the firing rate by $1.79 \pm 0.14 \mathrm{~Hz}$, whereas in the presence of both XE991 and apamin exposure to $15 \% \mathrm{CO}_{2}$ increased the firing rate by $3.17 \pm 0.48 \mathrm{~Hz}\left(T_{33}=-3.7, p<0.01\right)$ (Fig. $\left.1 E\right)$. Note that five cells were excluded from this analysis because they went into a depolarizing block when exposed to $15 \% \mathrm{CO}_{2}$ in the presence of both XE991 and apamin. These results suggest that SK channels provide a mechanism for scaling neuronal responsiveness to stimuli like $\mathrm{CO}_{2}$ when KCNQ channels are blocked. 

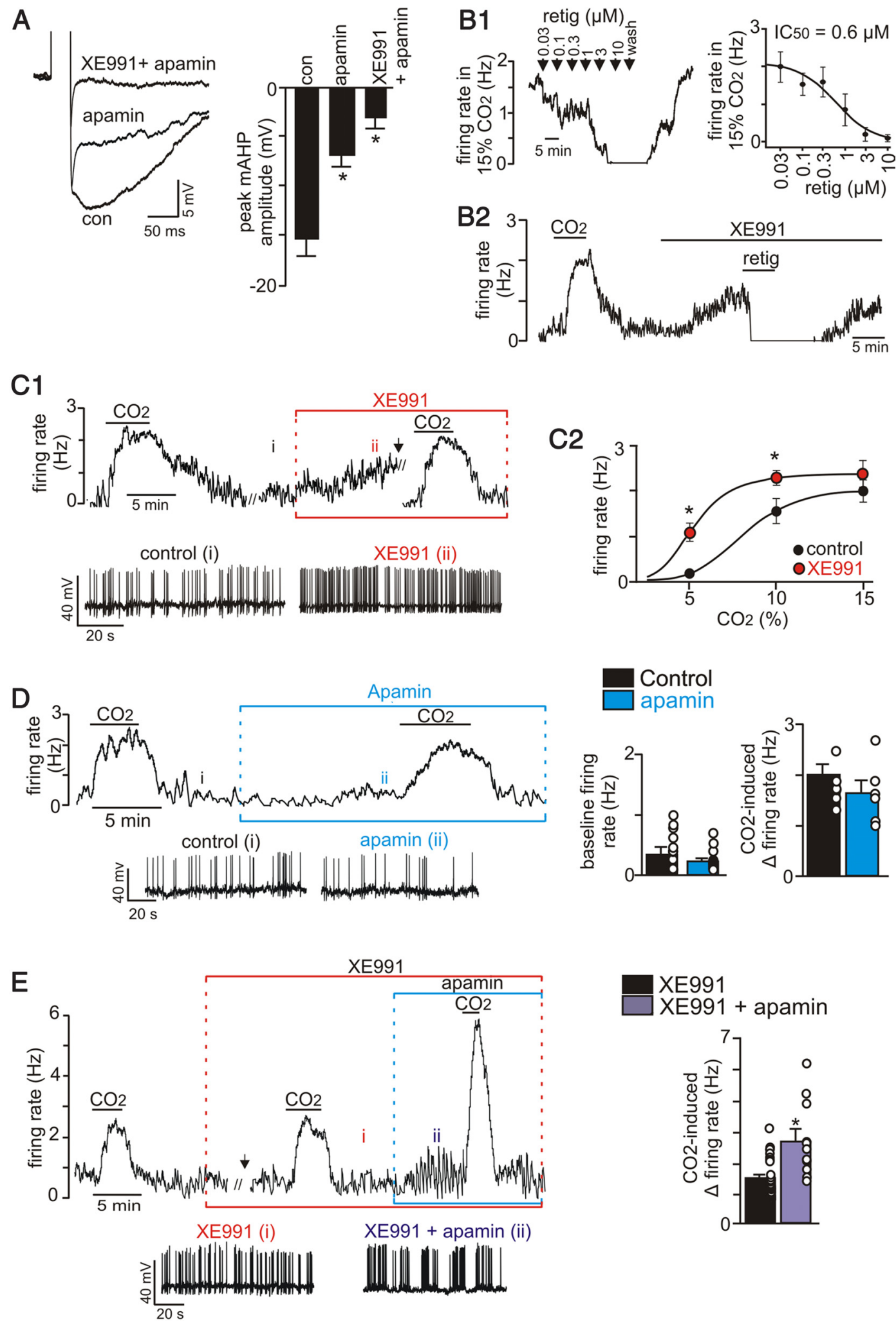

XE991

XE991 + apamin

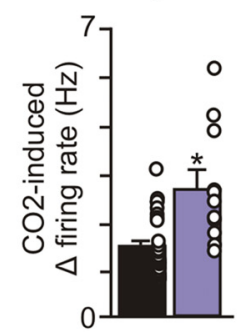

Figure 1. KCNQ and SK channels differentially regulate RTN chemoreceptor activity in vitro. $\boldsymbol{A}$, Left, Current traces show that RTN chemoreceptors exhibit a pronounced mAHP following depolarizing current injection $(100 \mathrm{~ms}, 1 \mathrm{nA})$ that could be reduced by apamin $(100 \mathrm{nM})$ and XE991 (10 $\mu \mathrm{M})$. Right, Summary data show peak mAHP amplitude in control, apamin, and XE991 ( $N=$ 7 cells/18 animals). B1, Left, Trace of firing rate from an RTN chemoreceptor shows the dose-dependent effects of retigabine (retig) on neuronal activity. Since RTN neurons have low basal activity, these experiments were performed in the continuous presence of $15 \% \mathrm{CO}_{2}$. Right, Summary data ( $\mathrm{N}=5$ cells/ 10 animals) fit using the Michaelis-Menten equation shows that RTN chemoreceptors have a retigabine $\mathrm{IC}_{50}$ of $0.6 \mu \mathrm{m} \pm 0.1$ (coefficient standard error; $R^{2}=0.964$ ). B2, Firing rate trace from an RTN chemoreceptor shows that bath application of XE991 ( $\left.2 \mu \mathrm{M}\right)$ increased activity $\sim 1.2$ $\mathrm{Hz}$. In the continued presence of XE991, subsequent application of retigabine $(40 \mu \mathrm{m})$ eliminated cell activity. $\mathbf{C 1}$, Firing rate trace shows the responses of an RTN chemoreceptor to $15 \% \mathrm{CO}_{2}$ under control conditions and in XE991. C2, Summary data ( $N=4$ cells/8 animals) fit using the Hill equation shows that XE991 increased activity at $5 \% \mathrm{CO}_{2}$ (i.e., baseline firing rate) and caused a left shift in the firing rate response to graded levels of $\mathrm{CO}_{2}$, but with no change in slope. Note that exposure to 10 and $15 \% \mathrm{CO}_{2}$ significantly increased activity under control and in XE991. Asterisks designate a significance difference between control and in XE991 as determined by one-way repeated-measures ANOVA ( $p<0.01$ ). D, Responses of an RTN chemoreceptor to 15\% (Figure legend continues.) 
The RTN receives extensive input from serotonergic neurons, and serotonin has been shown to increase chemoreceptor activity, in part by inhibition of an as-yet-unidentified potassium conductance (Mulkey et al., 2007b). Interestingly, the effects of XE991 on basal activity and $\mathrm{CO}_{2}$-dependent output of RTN neurons were similar to previously described effects of serotonin in these neurons (Mulkey et al., 2007b). In addition, serotonin has been shown to inhibit KCNQ channels (i.e., M-current) in other brain regions (Colino and Halliwell, 1987). Therefore, we wondered whether KCNQ channels serve as effectors for serotonergic modulation in the RTN. We first tested effects of serotonin on RTN neuron activity under control conditions and in the presence of XE991, the KCNQ channel-selective antagonist. Consistent with previous studies (Mulkey et al., 2007b), bath application of serotonin $(5 \mu \mathrm{M})$ increased RTN chemoreceptor baseline activity by $1.3 \pm 0.2 \mathrm{~Hz}\left(T_{6}=-4.2, p<0.01\right)$, and repeated applications consistently increased activity (ratio of the third serotonin response divided by the second response was $0.9 \pm 0.1$. However, serotonin only increased activity by $0.6 \pm$ $0.2 \mathrm{~Hz}$ in the presence of the KCNQ channel blocker XE991 (Fig. $2 A$ ), i.e., $\sim 50 \%$ of the increase seen in control conditions. In contrast, inhibition of SK channels with apamin had no effect on serotonin-induced firing (Fig. 2A). These results suggest that $\mathrm{KCNQ}$ channels are downstream targets of serotonergic signaling in RTN chemoreceptors. In addition, previous evidence suggests that serotonin may also activate an inward conductance in RTN neurons (Mulkey et al., 2007b). Consistent with this, preliminary results show that residual serotonin sensitivity in XE991 could be blocked by bath application of ZD7288 (10 $\mu \mathrm{M})$, a selective HCN channel blocker. For example, in XE991 and ZD7288, serotonin increased the firing rate by only $0.07 \pm 0.04\left(T_{8}=3.6, \mathrm{p}<0.05\right.$, $N=5$ ) (data not shown). In future studies we plan to explore the role of HCN channels in RTN chemoreceptor function; however, for the remainder of this study we focus on KCNQ channels.

Serotonergic neurons corelease thyrotropin-releasing hormone (TRH) and substance P (SP) with serotonin to activate RTN chemoreceptors (Mulkey et al., 2007b; Ptak et al., 2009). At other levels of the respiratory network (e.g., hypoglossal motor nucleus), serotonin, TRH, and SP have been shown to converge onto a common ion channel target (Talley et al., 2000). Therefore, we considered the possibility that KCNQ channels might act as downstream targets of TRH or SP. We found that the excitatory effects of TRH $\left(F_{(2,29)}=0.871, p=0.430\right)$ and SP $\left(F_{(2,13)}=\right.$ $0.263, p=0.773)$ were fully retained in the presence of XE991 or apamin (Fig. $2 B, C$ ), suggesting that RTN neurons respond to serotonin and TRH or SP by divergent mechanisms. Consistent with this possibility, firing rate responses to TRH and SP were fully retained in the presence of serotonin after baseline activity was adjusted to near control levels by DC injection (Fig. 2D). Thus, KCNQ channels underlie serotonergic, but not TRH or SP, modulation of RTN neurons.

$\leftarrow$

(Figure legend continued.) $\quad \mathrm{CO}_{2}$ under control conditions and in apamin. Right, Summary graph ( $N=6$ cells $/ 12$ animals) showing lack of apamin effect on baseline activity and $\mathrm{CO}_{2}$ sensitivity. Insets, Segments of membrane potential show effects of XE991 and apamin repetitive firing behavior. $\boldsymbol{E}$, Firing rate trace shows $\mathrm{CO}_{2}$ responsiveness under control conditions, in XE991 alone, and in XE991 plus apamin. Downward arrow $(\downarrow)$ designates DC current injection to approximate control level of activity. Insets, Segments of membrane potential show effects of XE991 alone and XE991 + apamin repetitive firing behavior. Right, Summary data $(N=10$ cells/ 30 animals) show $\mathrm{CO}_{2}$ responsiveness in XE991 alone and in XE991 plus apamin.

\section{KCNQ channels in the RTN regulate basal activity and} serotonin modulation respiratory drive in anesthetized rats

To further establish the physiological significance of KCNQ channels in the control of breathing, we tested the effects of XE991 on resting respiratory output and ventilatory responses to $\mathrm{CO}_{2}$ and serotonin in anesthetized and conscious animals. In anesthetized animals we found that bilateral RTN injections of XE991 (50 $\mu \mathrm{M}, 30 \mathrm{nl}$ each side) increased resting respiratory output as measured by a change in phrenic nerve discharge, PND. For example, application of XE991 into the RTN increased the neural equivalent of minute ventilation (mvPN, product of PND amplitude and frequency; $T_{5}=-14.445, p<0.001$ ) (Fig. $3 A, B$ ). Additionally, blocking KCNQ channels with XE991 shifted the $\mathrm{CO}_{2}$ threshold from $5.3 \pm 0.1$ to $4.5 \pm 0.1 \%\left(T_{10}=4.867, p<\right.$ 0.01 ) (Fig. $3 D$ ) and caused a parallel leftward shift in the $\mathrm{CO}_{2}$ ventilatory response curve $\left(F_{(11,42)}=112.3, p<0.01\right)$ (Fig. $\left.3 E\right)$, an effect similar to what we observed in vitro (Fig. $1 B$ ). Together, these data suggest that inhibition of KCNQ channels increases excitability of RTN chemoreceptors and consequently the responsiveness of the respiratory system to changes in $\mathrm{CO}_{2}$. However, our in vitro data also suggest that KCNQ channels do not contribute to the $\mathrm{CO}_{2} / \mathrm{H}^{+}$sensitive potassium conductance in RTN neurons (Fig. 1C). Consistent with this possibility, we found in adult animals that the ventilatory response to a maximum stimulus of $10 \% \mathrm{CO}_{2}$ was unaffected by application of XE991 into the RTN (Fig. 3C,E). In addition, we also tested effects of XE991 on $\mathrm{CO}_{2}$ responsiveness in young anesthetized animals (75-90 g, $N=3$ ). For these experiments diaphragmatic EMG was used to measure respiratory activity. The results of these experiments were entirely consistent with what we found in vitro and in anesthetized adult animals; bilateral RTN injections of XE991 (50 $\mu \mathrm{M})$ did not blunt the ventilatory response to $10 \% \mathrm{CO}_{2}\left(T_{8}=-0.261\right.$, $p=0.801$ ) (data not shown), further suggesting that KCNQ channels are not candidate $\mathrm{CO}_{2}$ sensors in these cells.

Next, we tested whether KCNQ channels expressed in the RTN contribute to serotonergic modulation of respiratory drive. As reported previously (Mulkey et al., 2007b), we found that unilateral injections of serotonin $(1 \mathrm{mM}$, this concentration is near the $\mathrm{EC}_{50}$ for hypoglossal motoneurons) into the RTN consistently increased PND amplitude in anesthetized animals (Figs. $3 G-I$ ), reflecting an increase in respiratory motor outflow. After respiratory activity returned to control levels due to serotonin clearance, injection of XE991 into the RTN attenuated subsequent effects of serotonin on respiratory output in these animals $\left(T_{8}=6.718, p<0.001\right)$ (Figs. 3G-I). Similar results were observed in young anesthetized animals $(75-90 \mathrm{~g}, N=3)$; unilateral RTN injection of XE991 $(50 \mu \mathrm{M})$ reduced the effects of serotonin on minute ventilation from $145 \pm 5.5$ to $120 \pm 2.6\left(T_{4}=7.276\right.$, $p<0.01)$ (data not shown). Taken together, these results demonstrate that KCNQ channels are important determinants of intrinsic excitability and serotonergic modulation of RTN chemoreceptors and respiratory drive.

\section{KCNQ channels in the RTN contribute to} serotonin-modulation of respiratory drive in conscious rats Although the RTN appears to be critically important for maintaining breathing during sleep, evidence from an animal model of central congenital hypoventilation syndrome- a condition resulting from abnormal chemoreception whose primary symptom is severe sleep apnea but otherwise normal breathing during wakefulness (Dubreuil et al., 2008)-suggests that this region has less of an impact on breathing in the awake state. Therefore, we hypothesized that KCNQ-mediated activation of the RTN will 
A
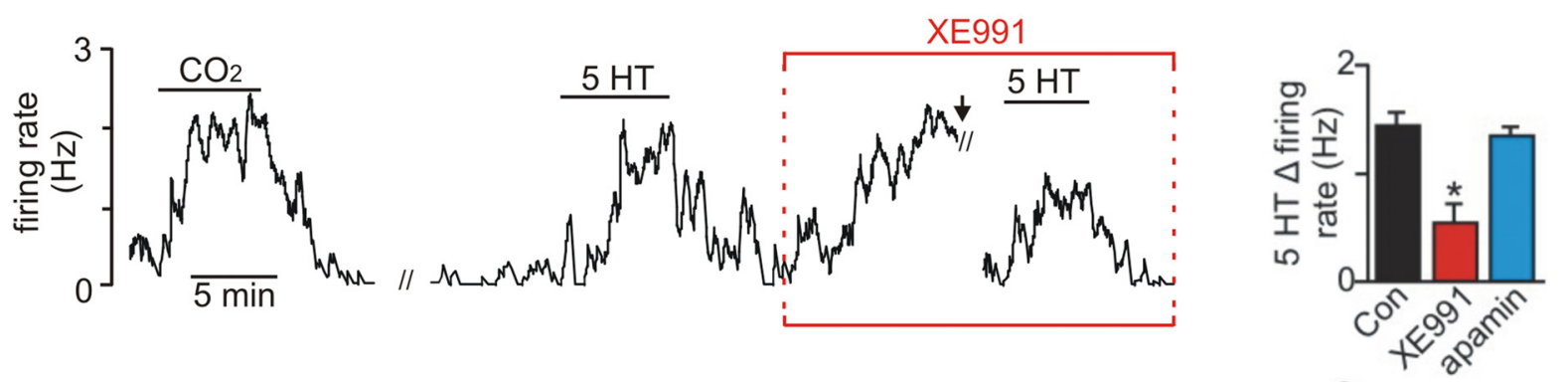

B
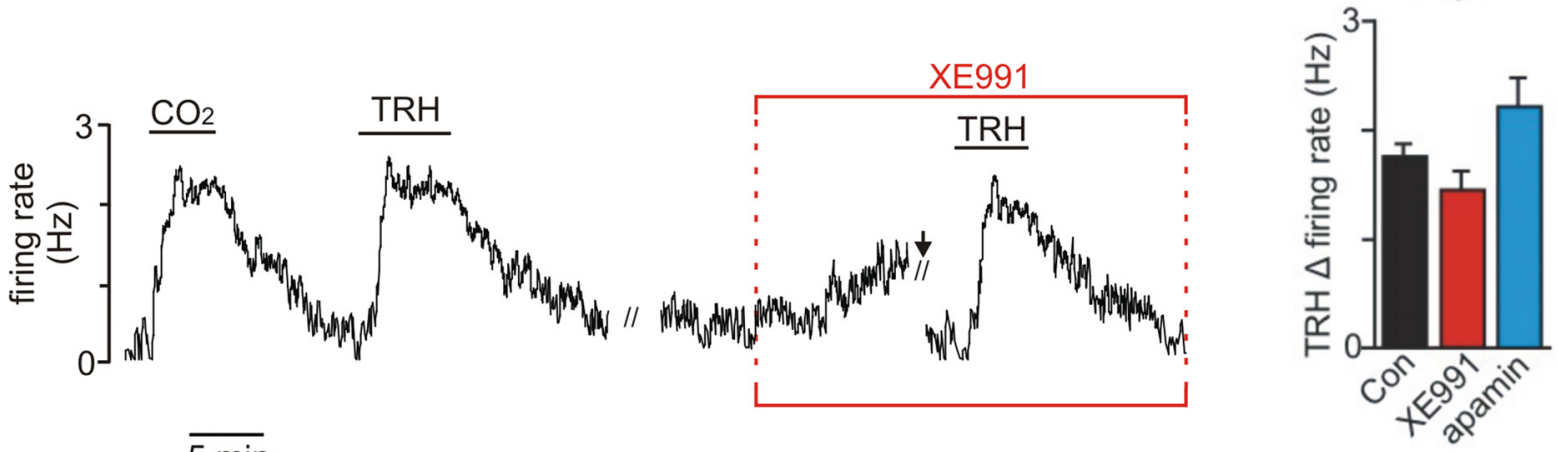

$\overline{5 \min }$

C
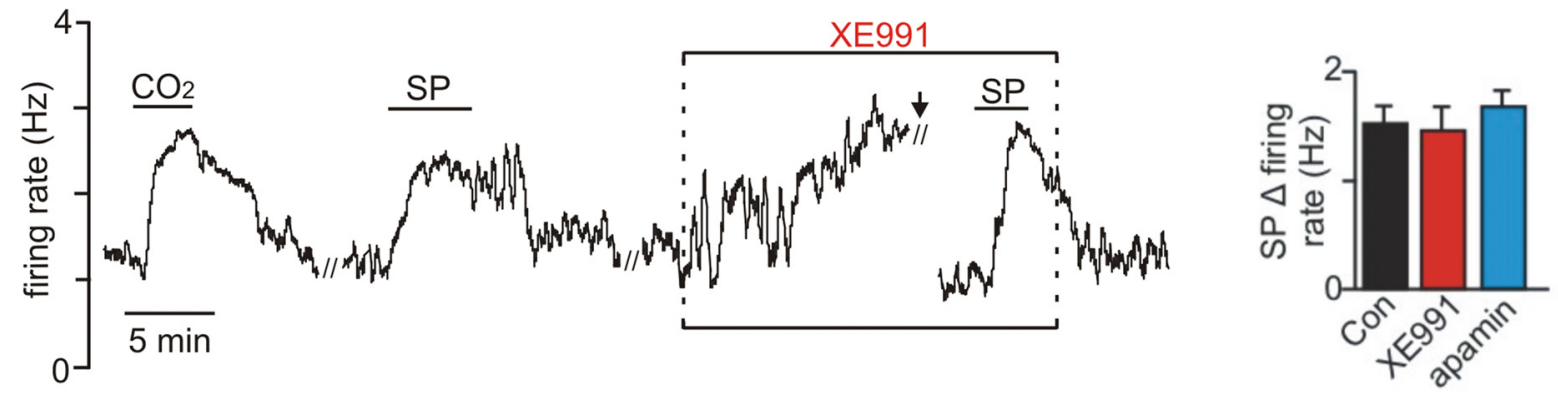

$\mathrm{D}$
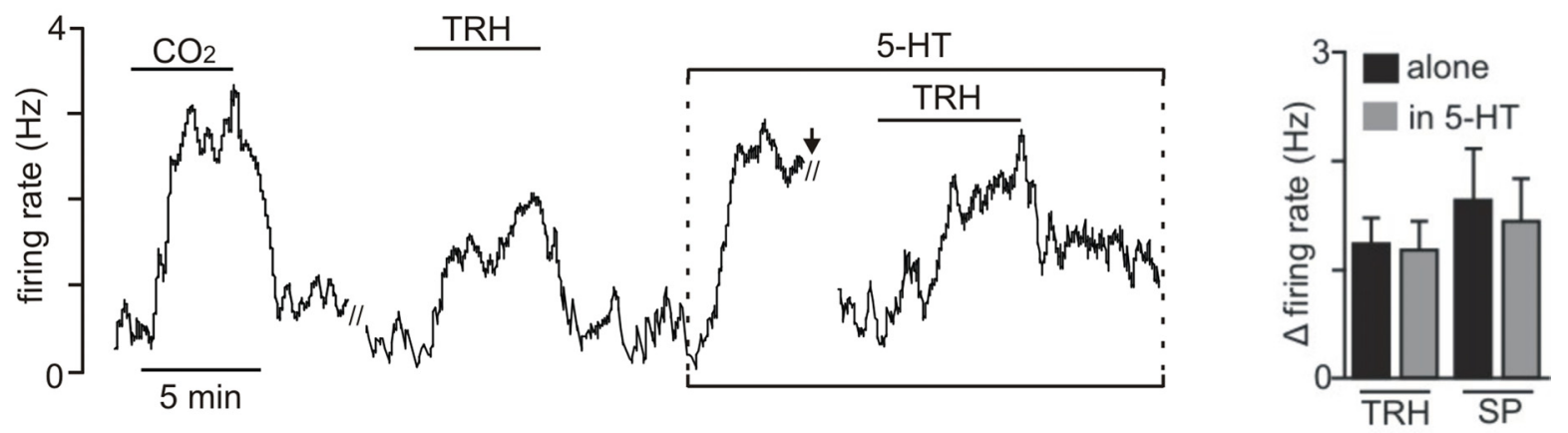

Figure 2. KCNQ channels mediate serotonergic modulation of RTN chemoreceptors in vitro. A-C, Firing rate traces (left) and summary data (right) show responses of RTN chemoreceptors to $5 \mu \mathrm{M}$ serotonin ( 5 -HT; $N=7$ cells $/ 14$ animals; $A)$, TRH ( $200 \mathrm{~nm} ; N=8$ cells $/ 16$ animals; $\boldsymbol{B})$, and SP $(0.5 \mu \mathrm{m} ; N=4$ cells $/ 9$ animals; $\boldsymbol{C}$ ) under control conditions and in XE991 (10 $\mu \mathrm{M})$. Summary graphs also show that apamin had no effect on firing rate response to $5-\mathrm{HT}(N=6$ cells $/ 14$ animals), TRH ( $N=7$ cells $/ 14$ animals), or $S P(N=5$ cells $/ 10$ animals). $D$, Left, Firing rate trace shows the response of a chemosensitive RTN neuron to TRH alone and in the presence of 5-HT. Summary data (right) show that RTN neurons can respond to 5-HT and TRH ( $N=4$ cells $/ 8$ animals) or SP ( $N=3$ cells/7 animals) independently of each other. Double slant bars (//) mark 10 min time breaks, and the downward arrow $(\downarrow)$ designates DC current injection.

minimally affect breathing in awake animals. Indeed, we found that bilateral injections of XE991 $(50 \mu \mathrm{M}, 50 \mathrm{nl}$ each side $)$ in awake animals had no measureable effect on baseline respiratory activity (Figs. $4 A, D$ ). Furthermore, bilateral RTN injections of XE991 did not affect the ventilatory response to $\mathrm{CO}_{2}$ in awake animals (Figs. $4 A-E$ ); this latter finding is consistent with observations made in the brain slices (Fig. $1 C$ ) and anesthetized animals (Figs. 3A-E).

The lack of effect of KCNQ channel inhibition on baseline respiratory activity in awake animals might also indicate that KCNQ channels do not control basal activity of RTN neurons in conscious animals. To examine this possibility, we tested whether awake animals respond to RTN injections of serotonin by a KCNQ-dependent mechanism. Unilateral injection of serotonin into the RTN of conscious animals increased minute ventilation (Fig. $4 J$ ) by increasing both tidal volume $\left(T_{5}=5.686, p<0.01\right)$ (Fig. $\left.4 F, H\right)$ and respiratory frequency $\left(T_{5}=4.226, p<0.01\right)$ (Fig. $\left.4 F, I\right)$. After respiratory activity returned to control levels, injection of XE991 into the RTN blunted subsequent serotonin responsiveness in these animals (Figs. $4 E-H)$, similar to its effect in anesthetized animals. Note that XE991 only partially blocked serotonin responsiveness, consistent with our in vitro results. Together, our work on functionally identified RTN 
A1 control

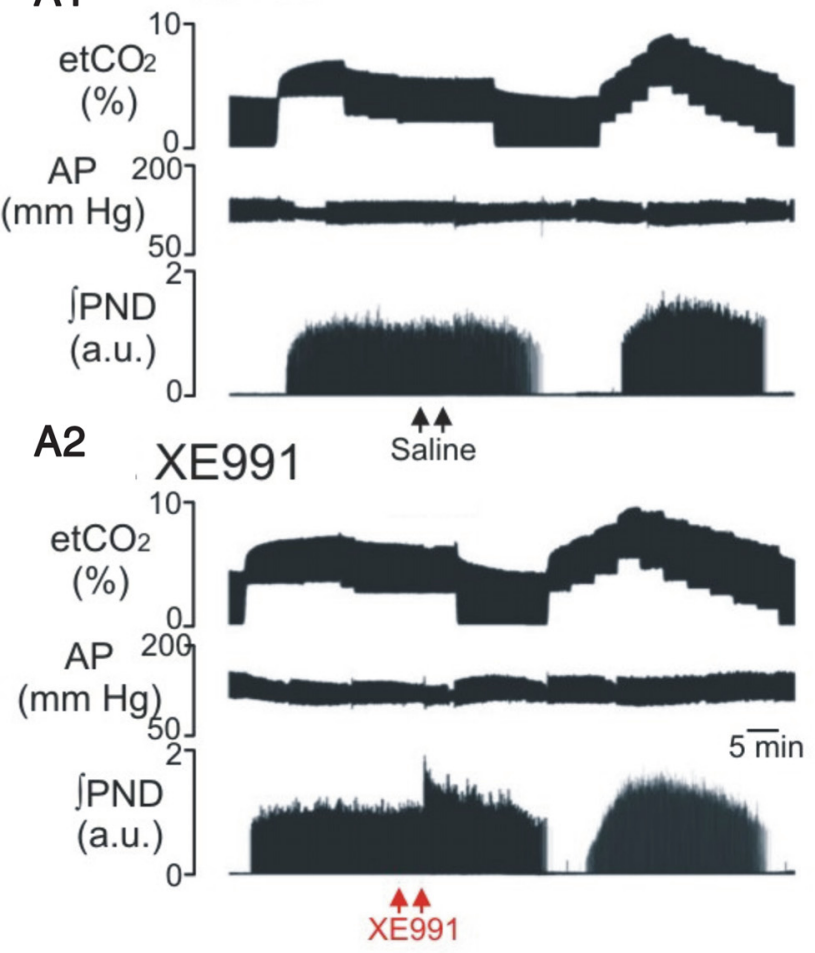

B

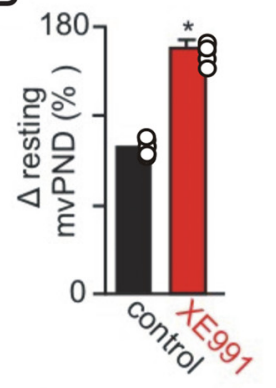

D

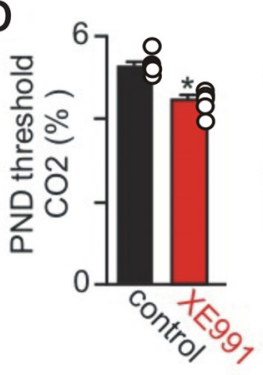

C

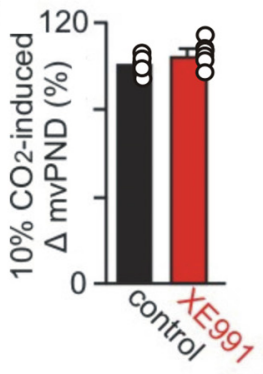

E

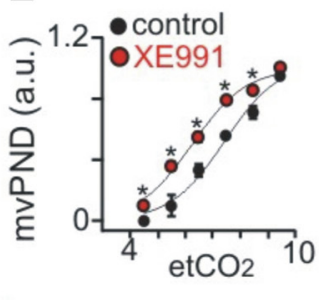

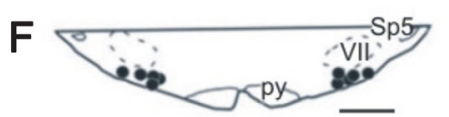

G
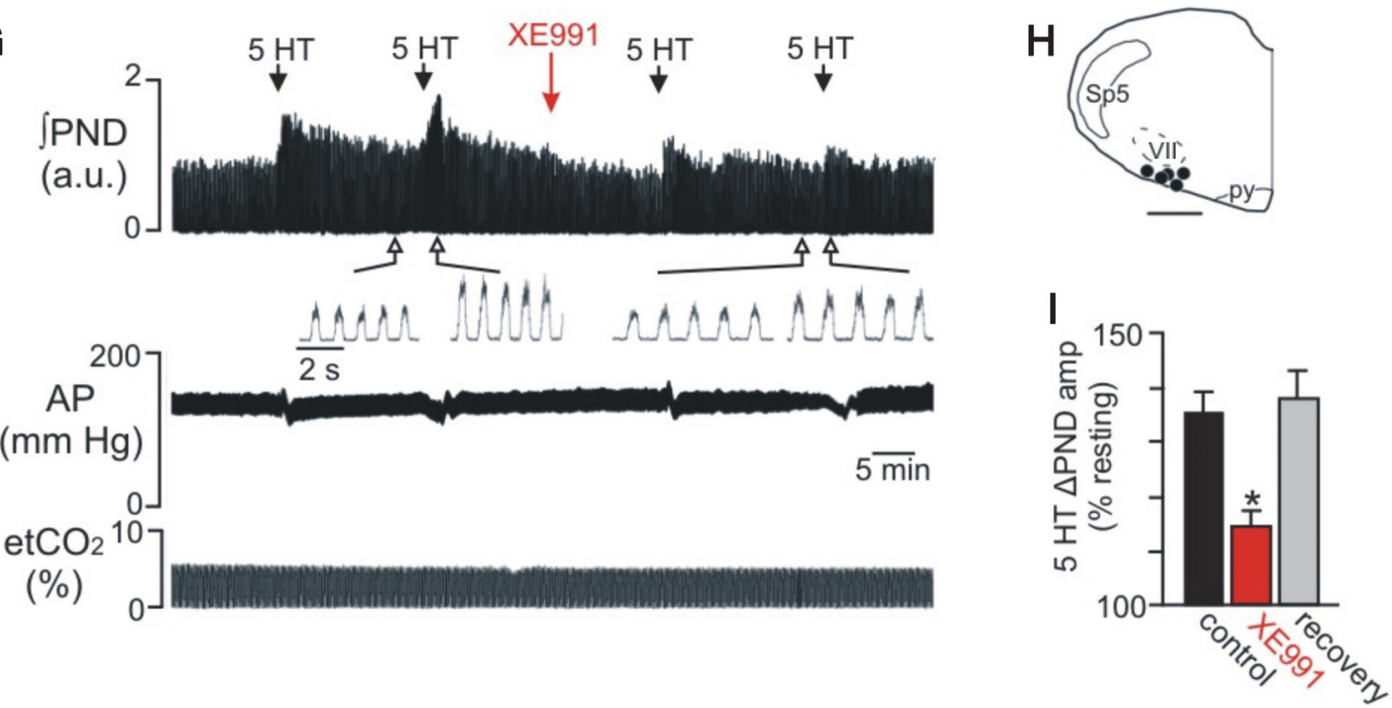

Figure 3. KCNQ channels in the RTN regulate resting and breathing activity and the ventilatory response to $\mathrm{CO}_{2}$ and serotonin in anesthetized rats. $A 1, A 2$, Traces of end expiratory $\mathrm{CO}_{2}$ (et $\mathrm{CO}_{2}$ ), arterial pressure (AP), and integrated phrenic nerve discharge ( $\int$ PND) show the ventilatory response to bilateral injections (arrows) of saline (A1) or XE991 (A2) into the RTN. Under control conditions, injections of XE991 ( $50 \mu \mathrm{m}, 30 \mathrm{nl}$ each side) increased resting breathing activity as evidenced by an increase in mvPND (product of PND amplitude and frequency) and significantly lowered the PND CO $\mathrm{C}_{2}$ threshold from $5.3 \pm 0.09 \%$ to $4.5 \pm 0.1 \%$. However, $\mathrm{CO}_{2}$ responsiveness was otherwise unaffected by application of XE991 into the RTN; lowering et $\mathrm{CO}_{2}$ from to $3-4 \%$ inhibited respiratory output, and graded increases et $\mathrm{C}_{2}$ up to $9-10 \%$ increased mvPND by an amount similar to that of saline controls. $\boldsymbol{B}$, Summary data plotted as change in mvPND show the effect of XE991 $(50 \mu \mathrm{M})$ on resting respiratory activity. $C$, Summary data showing $\mathrm{CO}_{2}$-induced changes in mvPND under control conditions and after injections of XE991. D, Summary data showing that XE991 decreased the level of $\mathrm{CO}_{2}$ required to stimulate PND activity. $E$, Summary data fit using the Hill equation shows that XE991 caused a left parallel shift in the $\mathrm{CO}_{2}$ ventilatory response curve. Asterisks designate a significant difference between control and in XE991 (one-way repeated measures ANOVA, $p<0.01, N=5$ rats). $F$, Computer-assisted plots of the center of the injection sites (coronal projection on the plane; bregma, -11.6; Paxinos and Watson, 1989). Note that all injections were made in the caudal aspect of the RTN, where there is the highest density of chemosensitive RTN neurons. G, Traces of $\int$ PND, AP, and et $\mathrm{CO}_{2}$ show that unilateral injection of XE 991 (50 $\left.\mu \mathrm{M}\right)$ into the RTN of an anesthetized rat decreased the normally robust excitatory effect of serotonin (5-HT) on PND amplitude. Injection of 5-HT (1 mM) caused a modest biphasic AP response that was unaffected by XE991. Inset, Traces of $\int$ PND show on an expanded time scale that injection of XE991 decreased effects of $5 \mathrm{HT}$ on PND amplitude with little effect on frequency. $\boldsymbol{H}$, Computer-assisted plot of XE991 injection sites in the caudal RTN. I, Summary data ( $N=5$ animals) show that injection of XE991 into the RTN reversibly decreased effects of 5-HT on PND amplitude. Note the effect of serotonin on PND fully recovered after washing XE991 for $\sim 1$ h. py, Pyramid; Sp5, spinal trigeminal tract; VII, facial motor nucleus. Scale bars, $1 \mathrm{~mm}$. 


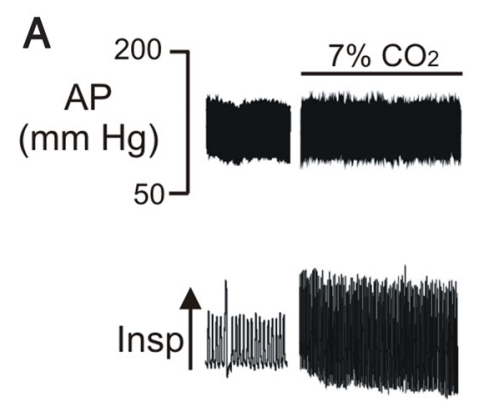

Saline

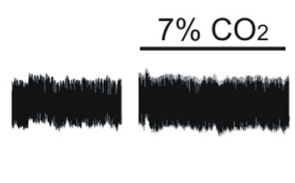

$1 \overline{\min }$

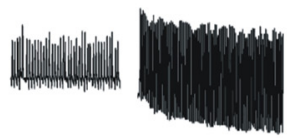

XE991
C

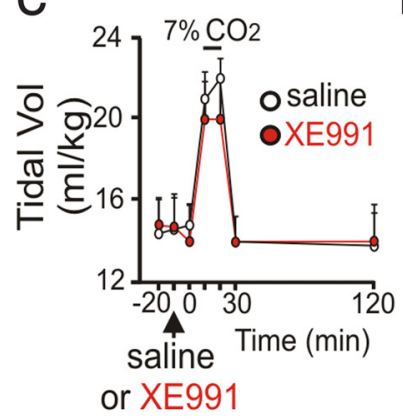

D

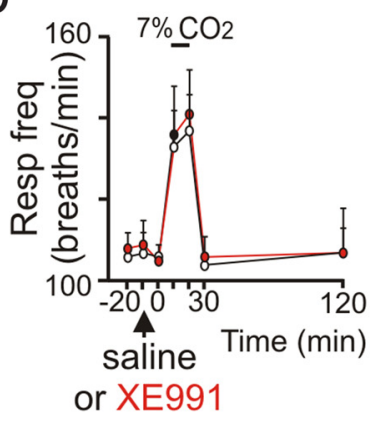

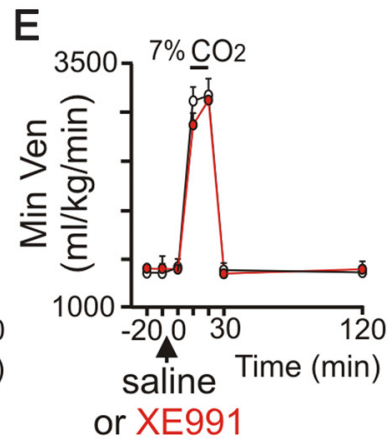

$\mathbf{F}$
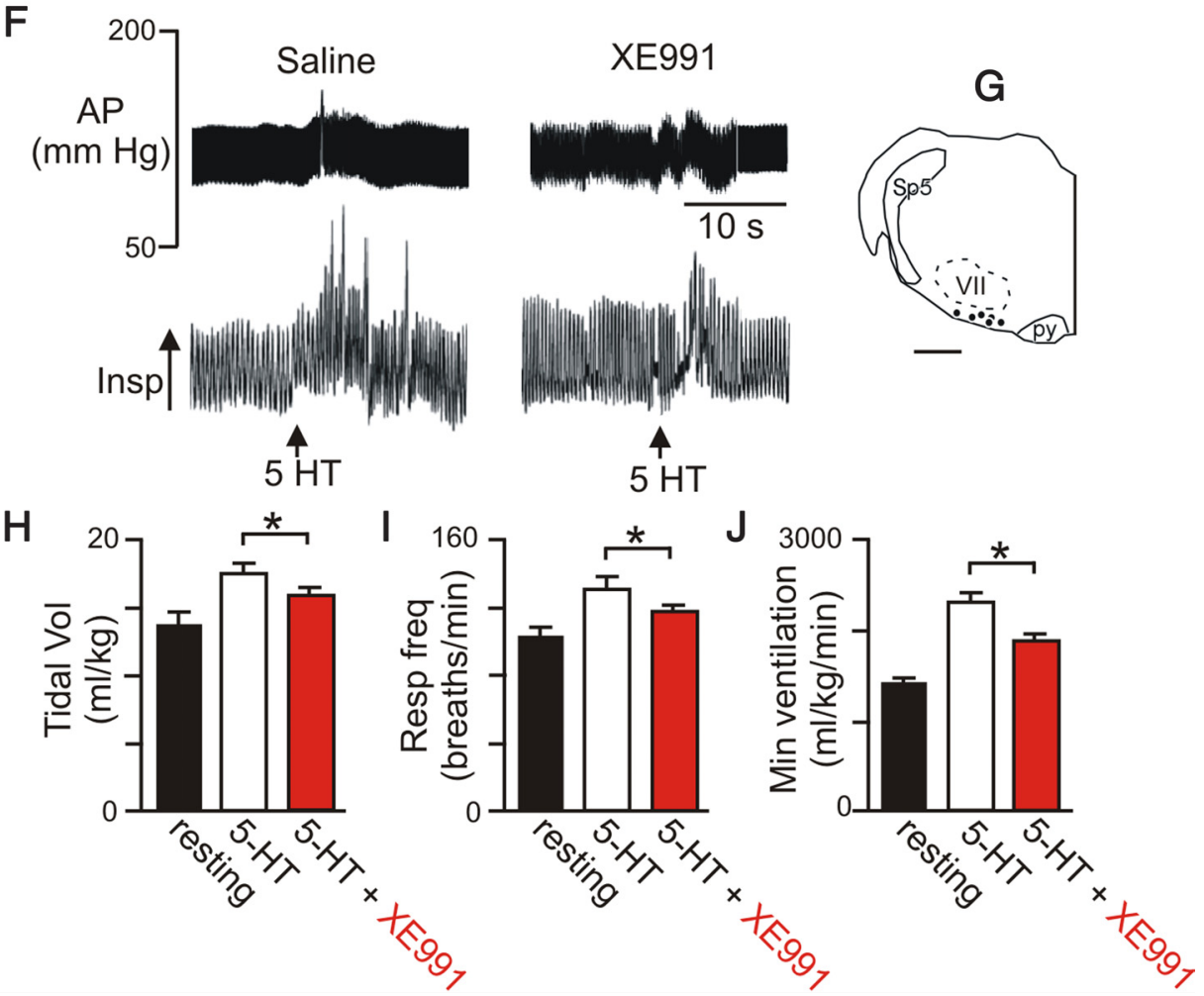

Figure 4. KCNQ channels in the RTN regulate the ventilatory response to exogenous serotonin in conscious awake rats. Whole-body plethysmography was used to measure respiratory rate (fR) and tidal volume (VT) in conscious, freely moving rats during exposure to hypercapnia $\left(7 \% \mathrm{CO}_{2}\right)$ after bilateral RTN injections of saline or XE991 (50 $\left.\mu \mathrm{M}\right)$. $\boldsymbol{A}$, Traces of arterial pressure, AP, and inspiratory (Insp) activity show respiratory activity after bilateral injections of saline or XE991 (50 $\mu \mathrm{m}$ ) under control conditions and in response to $7 \% \mathrm{CO}_{2}$. $\boldsymbol{B}$, Computer-assisted plot of XE991 injection sites in the RTN. py, Pyramid; VII, facial motor nucleus. Scale bar, $1 \mathrm{~mm}$. C-E, Summary data ( $N=6$ animals) plotted as VT (Tidal Vol; $\boldsymbol{C}$, fR (Resp freq; $\boldsymbol{D})$, or minute ventilation (Min Ven; $\boldsymbol{E}$ ) versus time show that RTN injections of XE991 had no effect on baseline breathing or the ventilatory response to $\mathrm{CO}_{2}$ in conscious rats. $\boldsymbol{F}$, Traces of AP and inspiratory activity show respiratory responses to injection of serotonin (1 mM) after unilateral injection of saline or XE991 (50 $\mu \mathrm{M})$. G, Plot of 5-HT and XE991 injection sites in the RTN. Scale bar, $1 \mathrm{~mm}$. $\boldsymbol{H}$-J, Summary data ( $N=6$ animals) show that unilateral RTN injection of XE991 decreased exogenous 5 -HT-induced (1 mM) increases in VT (H), fR (I), and minute ventilation $(\boldsymbol{J})$. 
neurons in brain slices and at the systems level in anesthetized and awake animals identifies KCNQ channels as critical determinants of RTN excitability and ultimately respiratory drive in a statedependent manner.

\section{Discussion}

Neurons in the RTN directly regulate breathing in response to changes in tissue $\mathrm{CO}_{2}$ and $\mathrm{H}^{+}$(Mulkey et al., 2004) and function as a nexus of respiratory control by integrating information from several respiratory centers, including the medullary raphe (Mulkey et al., 2007b). Despite the importance of RTN chemoreceptors in breathing, little is known regarding the ionic mechanisms that control RTN neuronal excitability and their exquisite responsiveness to neuromodulators. Here, we have shown that KCNQ channels in the RTN are (1) essential determinants of spontaneous activity in vitro, (2) downstream effectors of serotonergic modulation, and (3) affect respiratory drive in vivo in a state-dependent manner. These results build on the possibility originally proposed by Goldman et al. (2009) that KCNQ channels (i.e., KCNQ1) not only represent a common molecular basis for certain types of epilepsy and cardiac arrhythmias but now also respiratory deficits. However, our evidence that RTN chemoreceptors are highly sensitive to retigabine implicates KCNQ2-5 channels rather than retigabine-insensitive KCNQ1 channels.

KCNQ channels produce a subthreshold current (M-current) that can strongly influence neuronal excitability. For example, inhibition of the M-current can promote membrane depolarization, whereas its activation will hyperpolarize membrane potential and reduce neuronal excitability (Delmas and Brown, 2005). The M-current, together with SK channels, also prevents runaway neuronal activity by mediating the mAHP. We found that both SK and KCNQ channels mediate the mAHP in RTN neurons, similar to other neurons (Bond et al., 2004; Peters et al., 2005). However, KCNQ channels, but not SK channels, regulate tonic activity of RTN neurons. This effect may not be surprising considering that KCNQ channels are active at subthreshold membrane potentials, whereas SK channel opening requires bursts of action potentials and subsequent calcium influx. This role is further supported here by our finding that SK channels limit RTN activity when KCNQ channels are blocked. Importantly, we find that blocking KCNQ channels in the RTN of anesthetized animals increased sensitivity of the respiratory system to $\mathrm{CO}_{2}$ changes independent of the $\mathrm{CO}_{2} / \mathrm{H}^{+}$-sensing mechanism. This result suggests that KCNQ channels can regulate the intrinsic excitability of RTN chemoreceptors in vivo, and thus their ability to mediate respiratory responses to $\mathrm{CO}_{2}$. This also suggests that KCNQ channels are not the $\mathrm{CO}_{2} / \mathrm{H}^{+}$-sensitive potassium channels resident in RTN neurons. In addition, application of XE991 to inhibit KCNQ channels in awake behaving animals did not change respiratory output. This outcome is in-line with the proposal that the contribution of the RTN to respiratory drive is diminished during wakefulness (Guyenet, 2008). Future studies will be needed to measure the activity of RTN neurons in awake animals to directly determine whether KCNQ channels set their resting activity level under this condition.

It is well known that the serotonergic system exerts a profound effect on respiratory activity (Ptak et al., 2009; Ray et al., 2011). For instance, serotonergic neurons originating from raphe nuclei project to all levels of the respiratory network, including the RTN, the rhythm generating region pre-Bötzinger, as well as brainstem and spinal respiratory motor neurons. In all of these regions, how serotonin stimulates neural activity by activation of Gq-coupled and other raphe neurotransmitters (i.e., TRH and SP) in brains- tem respiratory centers is unclear. In the hypoglossal motor nucleus, the signaling pathways activated by raphe nuclei receptors initiate a signaling cascade that leads to multiple downstream effects, including inhibition of a subthreshold potassium conductance (Talley et al., 2000; Mulkey et al., 2007b; Ptak et al., 2009). Thus far, the identity of ion channels underlying responsiveness to serotonin transmitters converge to inhibit members of the KCNK family of background potassium channels called TASK-1 and TASK-3 (Talley et al., 2000). Although neither TASK-1 nor TASK-3 channels appear to modulate excitability of RTN chemoreceptors (Mulkey et al., 2007b), TASK-2 channels have been shown to influence basal activity (Gestreau et al., 2010). However, evidence that TASK-2 can be modulated by neurotransmitters is lacking. We now show that KCNQ channels are a major target of serotonin in RTN neurons. In particular, we found that blocking KCNQ channels with XE991, a selective KCNQ channel antagonist, reduced serotonin responsiveness of RTN neurons. This effect was seen both in vitro as well as in anesthetized and awake animals. The effects of XE991 and KCNQ channels were specific to serotonin, as blocking KCNQ channels did not preclude the excitatory effects of SP or TRH. This specificity was surprising, considering that these transmitters work though similar Gq-coupled signaling pathways and converge on similar targets in other brain regions (Talley et al., 2000). The ability of RTN neurons to respond independently to these various transmitters may enhance their integrative capacity and fine tuning of chemoreceptor activity.

In summary, our results show that KCNQ channels regulate intrinsic excitability and serotonergic modulation of RTN chemoreceptors and respiratory drive. These results provide unique insight into the molecular basis for transmitter modulation of RTN chemoreceptors and, to our knowledge, the first evidence that KCNQ channels are targets for neuromodulation in vivo.

\section{References}

Adelman JP, Maylie J, Sah P (2012) (2011) Small-conductance $\mathrm{Ca}^{2+}$. activated $\mathrm{K}^{+}$channels: form and function. Annu Rev Physiol 74:245-269. CrossRef Medline

Bond CT, Herson PS, Strassmaier T, Hammond R, Stackman R, Maylie J, Adelman JP (2004) Small conductance $\mathrm{Ca}^{2+}$-activated $\mathrm{K}^{+}$channel knock-out mice reveal the identity of calcium-dependent afterhyperpolarization currents. J Neurosci 24:5301-5306. CrossRef Medline

Brown DA, Adams PR (1980) Muscarinic suppression of a novel voltagesensitive $\mathrm{K}^{+}$current in a vertebrate neurone. Nature 283:673-676. CrossRef Medline

Buchanan GF, Richerson GB (2010) Central serotonin neurons are required for arousal to $\mathrm{CO}_{2}$. Proc Natl Acad Sci U S A 107:16354-16359. CrossRef Medline

Colino A, Halliwell JV (1987) Differential modulation of three separate $\mathrm{K}^{+}$-conductances in hippocampal CA1 neurons by serotonin. Nature 328:73-77. CrossRef Medline

Cooper EC, Harrington E, Jan YN, Jan LY (2001) M channel KCNQ2 subunits are localized to key sites for control of neuronal network oscillations and synchronization in mouse brain. J Neurosci 21:9529-9540. Medline

Delmas P, Brown DA (2005) Pathways modulating neural KCNQ/M (Kv7) potassium channels. Nat Rev Neurosci 6:850-862. CrossRef Medline

Dias MB, Li A, Nattie EE (2009) Antagonism of orexin receptor-1 in the retrotrapezoid nucleus inhibits the ventilatory response to hypercapnia predominantly in wakefulness. J Physiol 587:2059-2067. CrossRef Medline

Dubreuil V, Ramanantsoa N, Trochet D, Vaubourg V, Amiel J, Gallego J, Brunet JF, Goridis C (2008) A human mutation in Phox2b causes lack of $\mathrm{CO}_{2}$ chemosensitivity, fatal central apnea, and specific loss of parafacial neurons. Proc Natl Acad Sci U S A 105:1067-1072. CrossRef Medline

Favero MT, Takakura AC, de Paula PM, Colombari E, Menani JV, Moreira TS 
(2011) Chemosensory control by commissural nucleus of the solitary tract in rats. Respir Physiol Neurobiol 179:227-234. CrossRef Medline

Feldman JL, Mitchell GS, Nattie EE (2003) Breathing: rhythmicity, plasticity, chemosensitivity. Annu Rev Neurosci 26:239-266. CrossRef Medline

Fenik P, Veasey SC (2003) Pharmacological characterization of serotonergic receptor activity in the hypoglossal nucleus. Am J Respir Crit Care Med 167:563-569. CrossRef Medline

Gestreau C, Heitzmann D, Thomas J, Dubreuil V, Bandulik S, Reichold M, Bendahhou S, Pierson P, Sterner C, Peyronnet-Roux J, Benfriha C, Tegtmeier I, Ehnes H, Georgieff M, Lesage F, Brunet JF, Goridis C, Warth R, Barhanin J (2010) Task2 potassium channels set central respiratory $\mathrm{CO}_{2}$ and $\mathrm{O}_{2}$ sensitivity. Proc Natl Acad Sci U S A 107:2325-2330. CrossRef Medline

Goldman AM, Glasscock E, Yoo J, Chen TT, Klassen TL, Noebels JL (2009) Arrhythmia in heart and brain: KCNQ1 mutations link epilepsy and sudden unexplained death. Sci Transl Med 1:2ra6. CrossRef Medline

Guyenet PG (2008) The 2008 Carl Ludwig Lecture: retrotrapezoid nucleus, $\mathrm{CO}_{2}$ homeostasis, and breathing automaticity. J Appl Physiol 105: 404-416. CrossRef Medline

Malan A (1973) Ventilation measured by body plethysmography in hibernating mammals and in poikilotherms. Respir Physiol 17:32-44. CrossRef Medline

Mulkey DK, Stornetta RL, Weston MC, Simmons JR, Parker A, Bayliss DA, Guyenet PG (2004) Respiratory control by ventral surface chemoreceptor neurons in rats. Nat Neurosci 7:1360-1369. CrossRef Medline

Mulkey DK, Talley EM, Stornetta RL, Siegel AR, West GH, Chen X, Sen N, Mistry AM, Guyenet PG, Bayliss DA (2007a) TASK channels determine $\mathrm{pH}$ sensitivity in select respiratory neurons but do not contribute to central respiratory chemosensitivity. J Neurosci 27:14049-14058. CrossRef Medline

Mulkey DK, Rosin DL, West G, Takakura AC, Moreira TS, Bayliss DA, Guyenet PG (2007b) Serotonergic neurons activate chemosensitive retrotrapezoid nucleus neurons by a $\mathrm{pH}$-independent mechanism. J Neurosci 27:14128-14138. CrossRef Medline

Paxinos, G., Watson, C. (1989) The rat brain in stereotaxic coordinates, Ed 4. San Diego: Academic Press.

Perkins KL (2006) Cell-attacehd voltage-clamp and current-clamp recording and stimulation techniques in brain slices. J Neurosci Methods 154: 1-18. CrossRef Medline
Peters HC, Hu H, Pongs O, Storm JF, Isbrandt D (2005) Conditional transgenic suppression of $\mathrm{M}$ channels in mouse brain reveals functions in neuronal excitability, resonance and behavior. Nat Neurosci 8:51-60. CrossRef Medline

Ptak K, Yamanishi T, Aungst J, Milescu LS, Zhang R, Richerson GB, Smith JC (2009) Raphe neurons stimulate respiratory circuit activity by multiple mechanisms via endogenously released serotonin and substance P. J Neurosci 29:3720-3737. CrossRef Medline

Ray RS, Corcoran AE, Brust RD, Kim JC, Richerson GB, Nattie E, Dymecki SM (2011) Impaired respiratory and body temperature control upon acute serotonergic neuron inhibition. Science 333:637-642. CrossRef Medline

Sailer CA, Kaufmann WA, Marksteiner J, Knaus HG (2004) Comparative immunohistochemical distribution of three small-conductance $\mathrm{Ca}^{2+}$. activated potassium channel subunits, SK1, SK2, and SK3 in mouse brain. Mol Cell Neurosci 26:458-469. CrossRef Medline

Shapiro MS, Roche JP, Kaftan EJ, Cruzblanca H, Mackie K, Hille B (2000) Reconstitution of muscarinic modulation of the KCNQ2/KCNQ3 K(+) channels that underlie the neuronal M current. J Neurosci 20:1710-1721. Medline

Takakura AC, Moreira TS, Colombari E, West GH, Stornetta RL, Guyenet PG (2006) Peripheral chemoreceptor inputs to retrotrapezoid nucleus (RTN) $\mathrm{CO}_{2}$-sensitive neurons in rats. J Physiol 572:503-523. CrossRef Medline

Talley EM, Lei Q, Sirois JE, Bayliss DA (2000) TASK-1, a two-pore domain $\mathrm{K}^{+}$channel, is modulated by multiple neurotransmitters in motoneurons. Neuron 25:399-410. CrossRef Medline

Wang HS, Pan Z, Shi W, Brown BS, Wymore RS, Cohen IS, Dixon JE, McKinnon D (1998) KCNQ2 and KCNQ3 potassium channel subunits: molecular correlates of the M-channel. Science 282:1890-1893. CrossRef Medline

Wenker IC, Sobrinho CR, Takakura AC, Moreira TS, Mulkey DK (2012) Regulation of ventral surface $\mathrm{CO}_{2} / \mathrm{H}^{+}$-sensitive neurons by purinergic signalling. J Physiol 590:2137-2150. CrossRef Medline

Wickenden AD, Yu W, Zou A, Jegla T, Wagoner PK (2000) Retigabine, a novel anti-convulsant, enhances activation of KCNQ2/3 potassium channels. Mol Pharmacol 58:591-600. Medline 